Correspondence will be sent to Dr. Chao Liang

Email: cliang823@gmail.com

Tel: 86-18809873156 (Cell); Tel: 1-86-24-83978667 (office); Fax: 1-86-24-83870376

Institute of Applied Ecology, Chinese Academic of Sciences

Shenyang, 110016 P.R. China

\title{
Switchgrass rhizospheres stimulate microbial biomass but deplete microbial necromass in agricultural soils of the upper Midwest, USA
}

Chao Liang ${ }^{1,2} ; \quad$ Ederson da C. Jesus ${ }^{2,3} ; \quad$ David S. Duncan ${ }^{2,4} ; \quad$ John F. Quensen ${ }^{3} ; \quad$ Randall D. Jackson ${ }^{2,4}$; Teri C. Balser²; James M. Tiedje ${ }^{2,3}$

1 State Key Laboratory of Forest and Soil Ecology, Institute of Applied Ecology, Chinese Academy of Sciences, Shenyang 110164, China

2 DOE Great Lakes Bioenergy Research Center, University of Wisconsin-Madison, WI 53706, USA

3 Center for Microbial Ecology, Michigan State University, MI 48824, USA

4 Department of Agronomy, University of Wisconsin-Madison, WI 53706, USA

\begin{abstract}
:
Rhizosphere microbial communities play an essential role in determining plant productivity, particularly in agriculturally marginal environments. Perennial plants like switchgrass (Panicum virgatum) are thought to particularly influence microbial community composition and function within their rhizosphere. We compared microbial communities in switchgrass rhizospheres and their associated bulk soils in two regions of the U.S. upper Midwest (Michigan and Wisconsin) with contrasting soil types, and at two site types with differing switchgrass establishment ages and management intensities. We characterized microbial communities with a range of culture-independent methods, including amplicon sequencing of 16S/18S rRNA and nifH genes, and membrane lipid profiling. In addition, we quantified abundances of soil amino sugars, a time-integrative indicator of microbial necromass. We found that
\end{abstract}


amino sugar contents and microbial lipid profiles differed between rhizosphere and bulk soils, while DNA-based assays did not provide this discriminatory power. Differences between rhizosphere and bulk soils were not significantly affected by region or site type. Rhizosphere soils had higher microbial lipid abundances, particularly those associated with arbuscular mycorrhizal fungi and Gram-negative bacteria, while amino sugar abundances decreased in the rhizosphere. Our findings suggest switchgrass rhizospheres systematically stimulate microbial growth and microbial residue turnover.

Keywords: Pyrosequencing, nifH, Lipid, Amino sugar, Plant-microbe interaction, Rhizosphere, Switchgrass 


\section{Introduction}

To sustainably accommodate growing demand for both food and biologically-based fuels, it will be necessary to tap into and augment biomass production from agriculturally marginal lands (Gelfand et al., 2013). Beneficial microbial interactions in plant rhizospheres will be essential to achieving adequate plant productivity in these environments (Johansson et al., 2004). Novel molecular methodologies have granted new insights into the nature and composition of rhizosphere microbial communities (Philippot et al., 2013) although our knowledge of this complex system is far from complete (Frank and Groffman, 2009). Further improving our understanding of bioenergy crop rhizosphere communities will facilitate development of sustainably-productive, biologically-based fuel systems.

The plant rhizosphere is a highly dynamic environment within the soil milieu, with much of the activity revolving around exchanges of energy and nutrients. Root exudation and rhizodeposition furnish labile carbon, supporting increased microbial biomass and turnover (Joergensen, 2000; Buée et al., 2009), which spurs mineralization of soil organic matter and stable residues speeding nutrient turnover and potentially increasing nutrient availability (Kuzyakov, 2002). Many plants, notably warm-season perennial grasses, form symbiotic relationships with arbuscular mycorrhizal fungi (AMF) that can provide their hosts with greater access to phosphorus, nitrogen, and other key resources (Gianinazzi et al., 2010). A growing body of evidence indicates some potential bioenergy crop species may supplement their nitrogen supply through associations with nitrogen-fixing bacteria (Steenhoudt and Vanderleyden, 2000; Saravanan et al., 2008; Davis et al., 2009). While the species of the host plant plays a major role in shaping rhizosphere communities, factors such as soil type and management activities also contribute to determining microbial community composition and functionality (Garbeva et al., 2004; Berg and Smalla, 2009). It is thus necessary to understand not only how a crop's rhizosphere affects its associated microbiota, but also how that effect varies among soil and management contexts.

In this study we explore how the effects of switchgrass (Panicum virgatum L.) 
rhizospheres on their associated microbial communities are altered by soil type and agronomic management intensity. The study was conducted in two regions in the U.S. upper Midwest with comparable climate but distinct soil types; Soils from the Michigan (MI) region have significantly higher sand contents and lower fertility than those in the Wisconsin (WI) region (Jesus et al., 2015). In each region, we contrasted two site types: intensive sites in each state where switchgrass was recently established in replicated adjacent plots and was fertilized and harvested annually, and extensive sites located in different areas through both states where switchgrass had been established for at least 10 years and not regularly fertilized or harvested (Werling et al., 2014). We characterized the microbial community using three culture-independent molecular methods: pyrosequencing targeting the ribosomal genes of Archaea, Bacteria, Fungi, and lower Eukaryotes to analyze microbial community composition and structure; pyrosequencing targeting the nitrogen reductase (nifH) gene to specifically analyze the composition of nitrogen-fixing bacteria; and microbial cell membrane lipid profiling to characterize the living biomass of key functional groups (Jesus et al., 2015). We used cell wall amino sugars to quantify microbial residues in the intensive sites. These residues reflect time-integrated turnover of non-living microbial necromass, which plays a critical role in long-term soil carbon and nitrogen cycles (Guggenberger et al., 1999; Liang et al., 2015). This collection of methods enable us to analyze microbial community dynamics from multiple perspectives with a range of taxonomic and temporal resolutions.

Our aims in this study were to: 1) identify which microbial community metrics reflected rhizosphere influence; 2) determine whether rhizosphere influence differed between regions or site types; 3) describe rhizosphere effects on specific taxa and functional groups; and 4) measure the impact of the rhizosphere on microbial necromass abundance. This knowledge will improve our understanding of the factors that regulate soil microbial communities in switchgrass systems, and how consistently these effects can be extrapolated.

\section{Materials and methods}




\subsection{Site description and sampling}

Intensive sites were located at the Kellogg Biological Research Station (MI) and the Arlington Agricultural Research Station (WI), where they are planted as part of a replicated bioenergy cropping systems trial consisting of $c a \cdot 1,000-\mathrm{m}^{2}$ plots with 5 fully-randomized blocks, of which 3 were sampled 2 years after establishment for this study (Jesus et al., 2015). We used a network of extensive sites in both regions (MI and WI) where switchgrass had been established at least 10 years prior to sampling and which were selected to capture the range of soil conditions found in their respective region (Werling et al., 2014; Jesus et al., 2015). For this study, we randomly selected 4 MI sites and 3 WI sites from this network (Supplemental Figure $1)$.

For each sampled site, we arbitrarily selected 5 healthy switchgrass individuals, from which we obtained bulk soil and rhizosphere samples by compositing the individuals within a site. Bulk soil samples were taken from proximate bare ground with a 2-cm diameter soil corer to a depth of $10 \mathrm{~cm}$. The rhizosphere was functionally defined as the soil tightly adhering to roots after mild mechanical disturbance (Smalla et al., 2001). Collected samples were immediately placed on ice and stored at $4{ }^{\circ} \mathrm{C}$ until being homogenized and stored at $-20^{\circ} \mathrm{C}$. The soil physicochemical properties for the two site types in the both regions under switchgrass systems are presented in Table S1.

\subsection{Microbial and environmental measurements}

\subsubsection{Soil physicochemical measurements}

Soil samples were analyzed by the University of Wisconsin-Madison Soil and Plant Analysis Lab. Elemental composition (Al, B, Ca, Cu, Fe, K, Mg, Mn, Na, P, S and $\mathrm{Zn}$ ) was determined by inductively coupled plasma optical emission spectrometry (Jarrel Ash IRIS High Resolution ICP-OES). Total soil C and N contents were determined through combustion using a LECO-2000 analyzer. Soil pH was measured in a 1:1 water solution using a meter with a combination reference glass electrode. Soil texture was determined by hydrometer particle size analysis (Bouyoucos, 1962). 


\subsubsection{Amplification and sequencing of $16 S / 18 S$ rRNA genes}

DNA was extracted from $500 \mathrm{mg}$ of soil using Power Soil DNA Isolation Kits (Mobio Laboratories Inc.) according to the manufacturer's instructions and stored at $-20^{\circ} \mathrm{C}$ until use. Small ribosomal subunit (SSU) gene sequencing used $926 \mathrm{~F}$ and $1392 \mathrm{R}$ primers, which target $\sim 470 \mathrm{bp}$ of the V6-V8 region in both prokaryotes and eukaryotes (Lane, 1991; Engelbrektson et al., 2010). Samples were amplified in triplicate, pooled, size-selected by gel electrophoresis and purified prior to sequencing. Sequencing was conducted by the Joint Genome Institute using a GS FLX sequencer. Raw 16S/18S rRNA sequences were analyzed using the PyroTagger pipeline (http://pyrotagger.jgi-psf.org) with a $10 \%$ quality threshold and a minimum trimmed length of $150 \mathrm{bp}$ and clustered using the Markov Cluster algorithm as described in Engelbrektson et al. (2010). Clustered sequences were assigned to operational taxonomic units (OTUs) at 97\% identity. Taxonomic identity for each cluster was determined by the best hit in Greengenes (prokaryotic sequences) or Silva (eukaryotic sequences) databases. 16S/18S rRNA gene nucleotide sequences were deposited in the European Nucleotide Archive (http://www.ebi.ac.uk/ena) as part of two studies: study PRJEB10078 under accession numbers ERR975322 through ERR975333, for rhizosphere communities; and study PRJEB6704 under accession numbers EER571402 through ERR571405, ERR571415 through ERR571417, ERR571424 through ERR571426, ERR571437 and ERR571438, for bulk soil communities.

\subsection{3. nifH analysis}

DNA extracted from the soil samples served as template in triplicate PCR reactions performed using the Roche High Fidelity PCR system (Roche Diagnostics Gmbh, Mannheim, Germany) and bar-coded Poly primers (Poly et al., 2001). Procedures, sequencing and data processing were as previously described (Jesus et al., 2015). Raw nifH sequences were processed using the RDP FunGene pipeline (http://fungene.cme.msu.edu). Reads were frame shift corrected and translated to protein sequences using FrameBot (Wang et al., 2013). Within the FunGene pipeline, protein sequences were aligned using HMMER3 and clustered at 95\% identity using complete linkage clustering with mcClust (Fish et al., 2013). Representative sequences 
were classified in FunGene (Fish et al., 2013) to their nearest match from a curated reference set of 675 sequences (Wang et al., 2013). Sequences were deposited in the European Nucleotide Archive (http://www.ebi.ac.uk/ena) as part of two studies: study PRJEB10093 under accession numbers ERR977779 through ERR977791, for rhizosphere communities; and study PRJEB6704 under accession numbers ERR571359 through ERR571362, ERR571372 through ERR571374, ERR571381 through ERR571383, and ERR571393 through ERR571395, for bulk soil communities.

\subsubsection{Lipid analysis}

We used a hybrid procedure of phospholipid fatty acid (PLFA) and fatty acid methyl ester (FAME) analysis to assay microbial community composition (Kao-Kniffin and Balser, 2007; Liang et al., 2015). The MIDI EUKARY method database was used to identify fatty acids. We added 19:0 (nonadecanoic methyl ester) and 9:0 (nonanoic methyl ester) as internal standards to convert fatty acid peak areas to $\mathrm{nmol}$ lipid $\mathrm{g}^{-1}$ soil. Microbial biomass was estimated as the sum of all identifiable lipids with C12-C20. The abundance of different microbial groups was estimated using the abundance of signature lipids (Liang et al., 2012a; Liang et al., 2013).

\subsubsection{Amino sugar analysis}

The amino sugar analysis method was adapted from the protocol of Guerrant and Moss (1984), as modified by Zhang and Amelung (1996) and presented in greater detail by Liang et al. (2012b). Amino sugars were extracted and converted to aldononitrile acetates, and quantified with internal standard myo-inositol. Glucosamine (GluN) and muramic acid (MurA) were used to indicate fungal and bacterial residues, respectively; all individual amino sugars were summed to estimate the soil microbial necromass pool (Liang et al., 2013).

\subsection{Statistical analysis}

Data analysis was conducted in the $R$ statistical environment $(R, 2011)$. Soil property differences among field sites were assessed using unpaired t-tests. Multivariate analysis was conducted using the metaMDS and adonis functions of the 
vegan package (Oksanen et al., 2013) using Bray-Curtis distances calculated from relative abundances of $16 \mathrm{~S} / 18 \mathrm{~S}$ rRNA OTUs, nifH clusters, and microbial lipids. We tested the effects of geographic location, management intensity, and soil position on absolute abundances of microbial lipids and amino sugars using linear mixed models (LMMs) in the nlme package (Pinheiro et al., 2014). We used individual plots as a random term to account for the pairing of bulk and rhizosphere samples within a site.

\section{Results}

\subsection{Microbial community patterns by $16 \mathrm{~S} / 18 \mathrm{~S}$ rRNA gene sequences, nifH gene} $\underline{\text { sequences and lipid analysis }}$

Sequencing yields for the SSU rRNA dataset varied between 1074 to 19463 reads per sample with a median of 5252 reads. There was good coverage over the entire dataset (Good's coverage 0.96), but some individual samples were less thoroughly explored (Good's coverage 0.73 - 0.92). Although we employed universal primers that targeted both prokaryotes and eukaryotes, prokaryotic sequences comprised the overwhelming majority of our data (Fig. 1). We analyzed the rRNA profile of the entire microbial community, including low-abundance eukaryotic reads. In contrast to the low prevalence of fungal rRNA (1-8\% of total reads), fungal biomass formed a substantial component of the microbial lipid pool (Fig. 1). The most common bacterial phyla observed in the SSU rRNA dataset were Proteobacteria (23-40\%, median 26\%), Actinobacteria (8-24\%, median 19\%), and Acidobacteria (12-23\%, median 16\%). Sequencing yields were much more even for the nifH data (3638-6326 reads per sample). This nifH dataset was dominated by a small range of sequences: the 7 most abundant sequence clusters accounted for $51 \%$ of reads (Table S2). Good's coverage was $>0.99$ for all samples.

All of the methods used to characterize microbial community composition revealed that community-level patterns were significantly influenced by region (MI vs. WI) and site type (intensive vs. extensive) (Table 1). Only the nifH data lacked an interaction between region and site type. For SSU rRNA and nifH, data tended to cluster by region and site type, with rhizosphere communities strongly resembling 
those of their associated bulk soil (Fig. 2A, B). In contrast, microbial lipids exhibited consistent differences between bulk and rhizosphere soils (Fig. 2C). In both the SSU rRNA and the nifH data, variability among extensive site samples was greater than among intensive site samples; variability in the lipid data was generally consistent across treatments.

\subsection{Rhizosphere effects on microbial and functional group lipid biomass}

Total microbial and functional group lipid biomass were generally greater in the rhizosphere than in the bulk soil (Fig. 3A and 3B). At each location, fungal to bacterial lipid ratios were similar between rhizosphere and bulk soils (Fig. 3B). Lipid markers for AMF and Gram-negative (Gm-) bacteria were more abundant in rhizospheres than their associated bulk soils (Fig. 3C and 3D). AMF biomass was noticeably higher in the WI intensive site than in other locations (Fig. 3C). For both functional groups and total microbial biomass, rhizosphere effects were not significantly different between regions or between site types (Table 2 and Fig. 3).

\subsection{Rhizosphere effects on microbial residue amino sugars}

We only measured amino sugar abundances in the intensive sites. Total amino sugar abundance as well as the abundances of fungal residue biomarker GluN and bacterial residue biomarker MurA were significantly lower in the rhizosphere than the bulk soil (Fig. 4). These amino sugars also differed in abundance between two regions, although rhizosphere effects were not significantly different between regions (Table $3)$.

\section{Discussion}

\subsection{Biomass of AMF and Gm- bacteria increased in the rhizosphere}

We observed large and consistent rhizosphere effects on microbial lipid profile, largely from increased biomass of lipid markers for AMF and Gm- bacteria. These organisms exhibit greater incorporation of plant carbon than other taxa (Butler et al., 2003), although this effect may be lessened by nitrogen fertilization (Denef et al., 
2009). Biomass of AMF and Gm- bacteria increase in the bulk soil when rhizosphers are introduced, e.g., in potted plant experiments (Steer and Harris, 2000) and in field agricultural systems (Liang et al., 2012a), or expanded, as occurs when perennial grasses are established in previously agricultural soils (Herzberger et al., 2014), leading us to expect that overall soil microbial community of a site would reflect the duration of influence by perennial grass rhizospheres. This expectation was realized for $\mathrm{Gm}$ - bacteria, which were more abundant in the extensive sites with their longer histories of switchgrass establishment, but not for AMF, which were substantially more abundant at the WI intensive site. There is some indication that in prairie-derived soils AMF biomass increases rapidly in the years following establishment of perennial prairie species, but then decreases as the ecosystem continues to develop (Allison et al., 2005), suggesting the WI intensive site could become similar to the WI extensive sites over time. Even as overall AMF levels decline with site maturity, our findings indicate the rhizosphere continues to support greater AMF biomass than the surrounding bulk soils.

\subsection{Microbial necromass decreased in the rhizosphere}

Microbial residues play an important role in long-term soil carbon and nitrogen storage (Simpson et al., 2007; Liang and Balser, 2011). In earlier work we found that across sites, amino sugars were correlated to soil parameters, such as soil carbon and clay contents, and minimally related to membrane lipids (Liang et al., 2013). Within a site, however, the rhizosphere exhibits a substantial depletion of amino sugars alongside the increase in lipid biomass, similar to but larger than results reported by Appuhn et al. (2006). Plants are known to stimulate microbial activity and nutrient cycling, increasing mobilization of critical nutrients such as nitrogen from soil organic matter (Hamilton and Frank, 2001). Amino sugars are likely being mobilized and consumed as part of this process, which is not the case in the bulk soil. It is unclear whether this dynamic would change with system maturity or management intensity, as we only had amino sugars from the intensive sites. Nonetheless, it would be enlightening to further study the relative importance of amino sugars to plant nitrogen 
nutrition, as well as whether rhizosphere-enhanced turnover differs between microbial residues and other soil organic matter.

\subsection{Rhizosphere effects not observed in DNA-based microbial community metrics}

While switchgrass rhizospheres strongly affected microbial community lipid profiles, we saw no rhizosphere effects on rRNA or nifH profiles. There are multiple possible explanations, including the level of taxonomic resolution for each method, the actual community property measured, and the responsiveness of the underlying biomarkers to environmental change.

Lipid biomarkers can only distinguish very coarse groupings, typically above the phylum level, while SSU rRNA amplicon sequencing with universal primers can potentially identify microorganisms to the genus to species level (Kirk et al., 2004). Thus, the lipid data may reflect a rhizosphere benefit to Gm- bacteria in general while rRNA could show variability in which taxa within that group benefit the most.

SSU rRNA-based methods approximate relative counts of individuals, with some complications from $r r n$ copy number variability (Klappenbach et al., 2000), while lipid extraction estimates the absolute mass of different taxa. Compared to bacteria, fungal biomass per $r r n$ copy number is quite high, potentially explaining the disparity we observed in the representation of fungi in the lipid and SSU rRNA data. Fungi also exhibit protoplasmic streaming, in which active protoplasm is moved in the hyphae (Klein and Paschke, 2004), often under stress, which could affect sampling of its DNA and assessment of where activity resides. Moreover, much of the soil microbial population is dormant at any given time (Lennon and Jones, 2011). DNA-based profiles would be dominated by dormant individuals, while lipid profiling in principle primarily reflects active biomass.

The way lipid and DNA-based assessments reflect dormancy may underlie the difference in their assessment how responsive microbial communities are to their environment. Lipid profiles exhibit clear seasonal differences in some environments where 16S rRNA profiles do not (Jangid et al., 2010; Jangid et al., 2011). Similarly, Ritz et al. (2004) found microbial lipids were associated with vegetation composition 
and spatially structured at $\sim 1 \mathrm{~m}$ range in an upland grassland, while $16 \mathrm{~S}$ rRNA profiles showed no relationship to vegetation and were only spatially structured below the $8 \mathrm{~cm}$ scale. As seen in our results, lipid profiling characterize short-term changes in complex microbial communities that are not visible to DNA-based methods.

The lack of rhizosphere effects we observed in rRNA profiles may be partially due to rhizosphere dynamics in established perennial grasslands. These systems have very large root masses which turn over rapidly (Gill and Jackson, 2000). Much of the "bulk" soil in such a system was likely recently part of this large and fluctuating rhizosphere. Over time this could increase numbers of rhizosphere organisms throughout the soil. In areas outside of the rhizosphere at the time of sampling, many of these organisms would likely be dormant (Lennon and Jones, 2011), thus having reduced influence on the taxonomic composition of biomass but maintaining comparable numbers of individuals. In contrast, studies finding strong rhizosphere effects have typically been conducted in annual cropping systems (Costa et al., 2006; Peiffer et al., 2013) or recently established perennial systems (Singh et al., 2007; DeAngelis et al., 2008), where much of the bulk soil is unlikely to have recently experienced rhizosphere influence.

In addition, our use of multiple sites with distinct environmental properties may have precluded identification of a uniform rhizosphere effect on microbial community taxonomic composition. Soil is the primary reservoir for rhizosphere biodiversity (Berg and Smalla, 2009); rhizosphere bacterial and archaeal communities are shaped by their associated bulk soil communities (Bakker et al., 2015). Moreover, the extent, and even direction, of rhizosphere selection varies among soil types (Garbeva et al., 2004; Singh et al., 2007; Schreiter et al., 2014). We did not observe significant changes in rhizosphere effects between our two regions or site types. The variability among all of our sites, which were selected to reflect the range of soil types within the two regions (Jesus et al., 2015) and which had different establishment ages and management histories, likely overwhelmed the more subtle locale specific effect.

It should be noted that our rRNA dataset profiles the entire microbial community, due to our use of universal $16 \mathrm{~S} / 18 \mathrm{~S}$ primers, in contrast to the exclusive focus most 
other studies place on bacteria/archaea. Despite our use of universal primers, our rRNA dataset is dominated by bacteria, and thus largely reflects the dynamics of the same taxa that are typically observed in studies like ours. Prior studies have reported soil type strongly influences rhizosphere effects on microbial community composition (Garbeva et al., 2004; Berg and Smalla, 2009). In contrast to those findings, we did not observe significantly stronger or weaker rhizosphere effects between the two regions we studied (which have distinct soil types) or the site types therein. While there was a single intensive site per state, there were multiple extensive sites in each state, all with different times of establishment for their switchgrass stands and deliberately chosen to represent different soil types of the two regions (Jesus et al., 2015). Rhizosphere effects may have been overwhelmed by the variance among these sites due to differences in land use history and soil type (Steenwerth et al., 2002; Garbeva et al., 2008). The factors that limited detection of consistent rhizosphere effects on the taxonomic distribution of the soil microbial community likely also contributed to the limited influence of the rhizosphere on the distribution of nifH genes. Additionally, communities of $\mathrm{N}_{2}$-fixers associated with switchgrass are very diverse (Bahulikar et al., 2014), and nifH frequency is quite low in the rhizosphere metagenome of switchgrass ( $0.3 \%$ of the population, (Wang et al., 2015)), suggesting that the rhizosphere may not be an overly selective environment. This potentially weak selection may have been overwhelmed by the differences between sites. In particular, our two intensive sites had historically been used for agronomic trials, some involving legumes, so the legacy of these trials likely accounts for the systematic difference (Kulmatiski and Beard, 2011) between these sites and the extensive sites.

\section{Conclusions}

We found that the impact of switchgrass rhizospheres is more easily discerned from microbial biomass and necromass than from the genetic makeup of the associated soil microbial community. Our findings highlight how DNA- and biomass-based methods characterize microbial communities differently, as well as the benefits of combining 
both approaches. Rhizosphere effects did not differ significantly between regions or site types, suggesting plant roots may exert a relatively systematic influence on microbial community composition, biomass and residues. The coupled increase of microbial biomass and decrease of amino sugar abundances in rhizosphere soils suggests switchgrass promotes a larger microbial population with faster nutrient cycling, potentially improving plant access to nitrogen and other nutrients.

\section{Acknowledgments}

We thank Drs. Timothy Meehan and Hannah Gaines for assistance with field sampling, and Dr. Harry Read for analyzing lipid biomarkers. This work was supported by the DOE-Great Lakes Bioenergy Research Center (DOE BER Office of Science DE-FC02-07ER64494) and the National Natural Science Foundation of China (No. 41471218). 
Figure 1. Proportional abundances of bacteria and fungi in the $16 \mathrm{~S} / 18 \mathrm{~S}$ rRNA and membrane lipid datasets, plotted by samples.

Figure 2. Non-metric multidimensional scaling analysis of total operational taxonomic units (OTUs) as defined by clustering of 16/18S rRNA genes (A), total nifH genes (B), and total microbial community lipids (C). MI and WI refer to the region (Michigan and Wisconsin) where samples were collected, I and E refer to management intensive and extensive sites, and $\mathrm{R}$ denotes to rhizosphere samples. For example, MIIR indicates rhizosphere soil from the intensive site in MI.

Figure 3. Absolute abundance of fungi, bacteria, arbuscular mycorrhizal (AMF), saprophytic fungi (SF), Gram-positive (Gm+) and Gram-negative bacteria (Gm-), and the ratios of fungi/bacteria, $\mathrm{AMF} / \mathrm{SF}$ and $\mathrm{Gm}-/ \mathrm{Gm}+$ in bulk and rhizosphere soils under extensive and intensive management of switchgrass in Michigan and Wisconsin as determined by lipid analysis. Error bars represent standard errors. MI and WI refer to the region (Michigan and Wisconsin) where samples were collected, I and E refer to management intensive and extensive sites, and $\mathrm{R}$ denotes rhizosphere samples. For example, MII-R indicates rhizosphere soil from the intensive site in MI.

Figure 4. Absolute abundance in amino sugars and lipids in bulk and rhizosphere soils of intensive switchgrass systems in Michigan and Wisconsin. Error bars represent standard errors. MI and WI refer to the region (Michigan and Wisconsin) where samples were collected, and $\mathrm{R}$ denotes rhizosphere samples. For example, MII-R indicates rhizosphere soil from the intensive site in MI. 


\section{Reference}

1. Allison, V.J., Miller, R.M., Jastrow, J.D., Matamala, R., Zak, D.R., 2005. Changes in soil microbial community structure in a tallgrass prairie chronosequence. Soil Science Society of America Journal 69, 1412-1421.

2. Appuhn, A., Scheller, E., Joergensen, R.G., 2006. Relationships between microbial indices in roots and silt loam soils forming a gradient in soil organic matter. Soil Biology and Biochemistry 38, 2557-2564

3. Bahulikar, R.A., Torres-Jerez, I., Worley, E., Craven, K., Udvardi, M.K., 2014. Diversity of nitrogen-fixing bacteria associated with switchgrass in the native tallgrass prairie of northern Oklahoma. Applied and Environmental Microbiology 80, 5636-5643.

4. Bakker, M., Chaparro, J., Manter, D., Vivanco, J., 2015. Impacts of bulk soil microbial community structure on rhizosphere microbiomes of Zea mays. Plant and Soil 392, 115-126.

5. Berg, G., Smalla, K., 2009. Plant species and soil type cooperatively shape the structure and function of microbial communities in the rhizosphere. FEMS Microbiology Ecology 68, 1-13.

6. Bouyoucos, G.J., 1962. Hydrometer method improved for making particle size analysis of soils. Agronomy Journal 54, 464-465.

7. Buée, M., De Boer, W., Martin, F., van Overbeek, L., Jurkevitch, E., 2009. The rhizosphere zoo: an overview of plant-associated communities of microorganisms, including phages, bacteria, archaea, and fungi, and of some of their structuring factors. Plant and Soil 321, 189-212.

8. Butler, J.L., Williams, M.A., Bottomley, P.J., Myrold, D.D., 2003. Microbial community dynamics associated with rhizosphere carbon flow. Applied and Environmental Microbiology 69, 6793-6800

9. Costa, R., Götz, M., Mrotzek, N., Lottmann, J., Berg, G., Smalla, K., 2006. Effects of site and plant species on rhizosphere community structure as revealed by molecular analysis of microbial guilds. FEMS Microbiology Ecology 56, 236-249.

10. Davis, S.C., Parton, W.J., Dohleman, F.G., Smith, C.M., Grosso, S.D., Kent, A.D., DeLucia, E.H., 2009. Comparative biogeochemical cycles of bioenergy crops reveal nitrogen-fixation and low greenhouse gas emissions in a Miscanthus $\times$ giganteus agro-ecosystem. Ecosystems $13,144-156$.

11. DeAngelis, K.M., Brodie, E.L., DeSantis, T.Z., Andersen, G.L., Lindow, S.E., Firestone, M.K., 2008. Selective progressive response of soil microbial community to wild oat roots. ISME J 3 , 168-178.

12. Denef, K., Roobroeck, D., Manimel Wadu, M.C.W., Lootens, P., Boeckx, P., 2009. Microbial community composition and rhizodeposit-carbon assimilation in differently managed temperate grassland soils. Soil Biology and Biochemistry 41, 144-153.

13. Engelbrektson, A., Kunin, V., Wrighton, K.C., Zvenigorodsky, N., Chen, F., Ochman, H., Hugenholtz, P., 2010. Experimental factors affecting PCR-based estimates of microbial species richness and evenness. ISME J 4, 642-647.

14. Fish, J.A., Chai, B., Wang, Q., Sun, Y., Brown, C.T., Tiedje, J.M., Cole, J.R., 2013. FunGene: the functional gene pipeline and repository. Frontiers in Microbiology 4, 291.

15. Frank, D.A., Groffman, P.M., 2009. Plant rhizospheric N processes: what we don't know and why we should care. Ecology 90, 1512-1519.

16. Garbeva, P., van Elsas, J., van Veen, J., 2008. Rhizosphere microbial community and its 
response to plant species and soil history. Plant and Soil 302, 19-32.

17. Garbeva, P., van Veen, J.A., van Elsas, J.D., 2004. Microbial diversity in soil: selection of microbial populations by plant and soil type and implications for disease suppressiveness. Annual Review of Phytopathology 42, 243-270.

18. Gelfand, I., Sahajpal, R., Zhang, X., Izaurralde, R.C., Gross, K.L., Robertson, G.P., 2013. Sustainable bioenergy production from marginal lands in the US Midwest. Nature 493, 514-517.

19. Gianinazzi, S., Gollotte, A., Binet, M.-N., van Tuinen, D., Redecker, D., Wipf, D., 2010. Agroecology: the key role of arbuscular mycorrhizas in ecosystem services. Mycorrhiza 20, 519-530.

20. Gill, R.A., Jackson, R.B., 2000. Global patterns of root turnover for terrestrial ecosystems. New Phytologist 147, 13-31.

21. Guerrant, G.O., Moss, C.W., 1984. Determination of monosaccharides as aldononitrile, O-methyloxime, alditol, and cyclitol acetate derivatives by gas-chromatography. Analytical Chemistry 56, 633-638.

22. Guggenberger, G., Frey, S., Six, J., Paustian, K., Elliott, E., 1999. Bacterial and fungal cell-wall residues in conventional and no-tillage agroecosystems. Soil Sci Soc Am J 63, 1188-1198.

23. Hamilton, E.W., Frank, D.A., 2001. Can plants stimulate soil microbes and their own nutrient supply? Evidence from a grazing tolerant grass. Ecology 82, 2397-2402.

24. Herzberger, A.J., Duncan, D.S., Jackson, R.D., 2014. Bouncing back: plant-associated soil microbes respond rapidly to prairie establishment. PLoS ONE 9, e115775.

25. Jangid, K., Williams, M.A., Franzluebbers, A.J., Blair, J.M., Coleman, D.C., Whitman, W.B., 2010. Development of soil microbial communities during tallgrass prairie restoration. Soil Biology and Biochemistry 42, 302-312.

26. Jangid, K., Williams, M.A., Franzluebbers, A.J., Schmidt, T.M., Coleman, D.C., Whitman, W.B., 2011. Land-use history has a stronger impact on soil microbial community composition than aboveground vegetation and soil properties. Soil Biology and Biochemistry 43, 2184-2193.

27. Jesus, d.C.E., Liang, C., Quensen, J.F., Susilawati, E., Jackson, R.D., Balser, T.C., Tiedje, J.M., 2015. Influence of corn, switchgrass, and prairie cropping systems on soil microbial communities in the upper Midwest of the United States. GCB-Bioenergy DOI: 10.1111/gcbb.12289.

28. Joergensen, R.G., 2000. Ergosterol and microbial biomass in the rhizosphere of grassland soils. Soil Biology and Biochemistry 32, 647-652.

29. Johansson, J.F., Paul, L.R., Finlay, R.D., 2004. Microbial interactions in the mycorrhizosphere and their significance for sustainable agriculture.

30. Kao-Kniffin, J., Balser, T.C., 2007. Elevated $\mathrm{CO}_{2}$ differentially alters belowground plant and soil microbial community structure in reed canary grass-invaded experimental wetlands. Soil Biology and Biochemistry 39, 517-525.

31. Kirk, J.L., Beaudette, L.A., Hart, M., Moutoglis, P., Klironomos, J.N., Lee, H., Trevors, J.T., 2004. Methods of studying soil microbial diversity. Journal of Microbiological Methods 58, 169-188.

32. Klappenbach, J.A., Dunbar, J.M., Schmidt, T.M., 2000. rRNA operon copy number reflects 
ecological strategies of bacteria. Applied and Environmental Microbiology 66, 1328-1333.

33. Klein, D.A., Paschke, M.W., 2004. Filamentous fungi: the indeterminate lifestyle and microbial ecology. Microbial Ecology 47, 224-235.

34. Kulmatiski, A., Beard, K.H., 2011. Long-term plant growth legacies overwhelm short-term plant growth effects on soil microbial community structure. Soil Biology and Biochemistry 43, 823-830.

35. Kuzyakov, Y., 2002. Review: factors affecting rhizosphere priming effects. Journal of Plant Nutrition and Soil Science 165, 382-396.

36. Lane, D.J., 1991. 16S/23S rRNA sequencing, In: Stackebrandt, E., Goodfellow, M. (Eds.), Nucleic Acid Techniques in Bacterial Systematics. Wiley, Chichester, UK, pp. 115-175.

37. Lennon, J.T., Jones, S.E., 2011. Microbial seed banks: the ecological and evolutionary implications of dormancy. Nat Rev Micro 9, 119-130.

38. Liang, C., Balser, T.C., 2011. Microbial production of recalcitrant organic matter in global soils: implications for productivity and climate policy. Nat Rev Micro 9, 75.

39. Liang, C., Duncan, D.S., Balser, T.C., Tiedje, J.M., Jackson, R.D., 2013. Soil microbial residue storage linked to soil legacy under biofuel cropping systems in southern Wisconsin, USA. Soil Biology and Biochemistry 57, 939-942.

40. Liang, C., Gutknecht, J., Balser, T., 2015. Microbial lipid and amino sugar responses to long-term simulated global environmental changes in a California annual grassland. Frontiers in Microbiology 6, 385 .

41. Liang, C., Jesus, E.d.C., Duncan, D.S., Jackson, R.D., Tiedje, J.M., Balser, T.C., 2012a. Soil microbial communities under model biofuel cropping systems in southern Wisconsin, USA: Impact of crop species and soil properties. Applied Soil Ecology 54, 24-31.

42. Liang, C., Read, H.W., Balser, T.C., 2012b. GC-based detection of aldononitrile acetate derivatized glucosamine and muramic acid for microbial residue determination in soil. Journal of Visualized Experiment, e3767.

43. Oksanen, J., Blanchet, F.G., Kindt, R., Legendre, P., Minchin, P.R., O'Hara, R.B., Simpson, G.L., Solymos, P., Stevens, M.H.H., Wagner, H., 2013. Vegan: community ecology package, R package version 2.0-6, 2.0-6 ed.

44. Peiffer, J.A., Spor, A., Koren, O., Jin, Z., Tringe, S.G., Dangl, J.L., Buckler, E.S., Ley, R.E., 2013. Diversity and heritability of the maize rhizosphere microbiome under field conditions. Proceedings of the National Academy of Sciences 110, 6548-6553.

45. Philippot, L., Raaijmakers, J.M., Lemanceau, P., van der Putten, W.H., 2013. Going back to the roots: the microbial ecology of the rhizosphere. Nat Rev Micro 11, 789-799.

46. Pinheiro, J., Bates, D., DebRoy, S., Sarkar, D., 2014. nlme: linear and nonlinear mixed effects models, In: Team, R.C. (Ed.), 2.0-6 ed.

47. Poly, F., Monrozier, L.J., Bally, R., 2001. Improvement in the RFLP procedure for studying the diversity of nifH genes in communities of nitrogen fixers in soil. . Research In Microbiology 152, 95-103.

48. R, 2011. R: A language and environment for statistical computing, Vienna, Austria.

49. Ritz, K., McNicol, J.W., Nunan, N., Grayston, S., Millard, P., Atkinson, D., Gollotte, A., Habeshaw, D., Boag, B., Clegg, C.D., Griffiths, B.S., Wheatley, R.E., Glover, L.A., McCaig, A.E., Prosser, J.I., 2004. Spatial structure in soil chemical and microbiological properties in an upland grassland. FEMS Microbiology Ecology 49, 191-205. 
50. Saravanan, V.S., Madhaiyan, M., Osborne, J., Thangaraju, M., Sa, T.M., 2008. Ecological occurrence of gluconacetobacter diazotrophicus and nitrogen-fixing Acetobacteraceae members: their possible role in plant growth promotion. Microbial Ecology 55, 130-140.

51. Schreiter, S., Sandmann, M., Smalla, K., Grosch, R., 2014. Soil type dependent rhizosphere competence and biocontrol of two bacterial inoculant strains and their effects on the rhizosphere microbial community of field-grown lettuce. PLoS ONE 9, e103726.

52. Simpson, A., J,, Simpson, M.J., Smith, E., Kelleher, B.P., 2007. Microbially derived inputs to soil organic matter: are current estimates too low? Environ. Sci. Technol. 41, 8070-8076.

53. Singh, B.K., Munro, S., Potts, J.M., Millard, P., 2007. Influence of grass species and soil type on rhizosphere microbial community structure in grassland soils. Applied Soil Ecology 36, 147-155.

54. Smalla, K., Wieland, G., Buchner, A., Zock, A., Parzy, J., Kaiser, S., Roskot, N., Heuer, H., Berg, G., 2001. Bulk and rhizosphere soil bacterial communities studied by denaturing gradient gel electrophoresis: plant-dependent enrichment and seasonal shifts revealed. Appl. Environ. Microbiol. 67, 4742-4751.

55. Steenhoudt, O., Vanderleyden, J., 2000. Azospirillum, a free-living nitrogen-fixing bacterium closely associated with grasses: genetic, biochemical and ecological aspects. FEMS Microbiology Reviews 24, 487-506.

56. Steenwerth, K.L., Jackson, L.E., Calderon, F.J., Stromberg, M.R., Scow, K.M., 2002. Soil microbial community composition and land use history in cultivated and grassland ecosystems of coastal California. Soil Biology and Biochemistry 34, 1599-1611.

57. Steer, J., Harris, J.A., 2000. Shifts in the microbial community in rhizosphere and non-rhizosphere soils during the growth of Agrostis stolonifera. Soil Biology and Biochemistry 32, 869-878.

58. Wang, Q., Fish, J.A., Gilman, M., Sun, Y., Brown, C.T., Tiedje, J.M., Cole, J.R., 2015. Xander: employing a novel method for efficient gene-targeted metagenomic assembly. Microbiome, DOI 10.1186/s40168-40015-40093-40166.

59. Wang, Q., Quensen, J.F., Fish, J.A., Kwon Lee, T., Sun, Y., Tiedje, J.M., Cole, J.R., 2013. Ecological patterns of nifH genes in four terrestrial climatic zones explored with targeted metagenomics using FrameBot, a new informatics tool. mBio 4, e00592-00513.

60. Werling, B.P., Dickson, T.L., Isaacs, R., Gaines, H., Gratton, C., Gross, K.L., Liere, H., Malmstrom, C.M., Meehan, T.D., Ruan, L., Robertson, B.A., Robertson, G.P., Schmidt, T.M., Schrotenboer, A.C., Teal, T.K., Wilson, J.K., Landis, D.A., 2014. Perennial grasslands enhance biodiversity and multiple ecosystem services in bioenergy landscapes. Proceedings of the National Academy of Sciences 111, 1652-1657.

61. Zhang, X., Amelung, W., 1996. Gas chromatographic determination of muramic acid, glucosamine, mannosamine, and galactosamine in soils. Soil Biology and Biochemistry 28, 1201-1206. 
Table 1. Multivariate analysis of variance for three soil microbial community measures.

\begin{tabular}{|c|c|c|c|c|c|c|}
\hline & \multicolumn{2}{|c|}{ SSU rRNA } & \multicolumn{2}{|c|}{ nifH sequence } & \multicolumn{2}{|c|}{ Lipid } \\
\hline & $\mathrm{R}^{2}$ & F value & $\mathrm{R}^{2}$ & F value & $\mathrm{R}^{2}$ & F value \\
\hline Region (R) & 0.07 & $1.82 * *$ & 0.16 & $5.00 * * *$ & 0.12 & $6.86 * * *$ \\
\hline Site type (S) & 0.11 & $2.92 * * *$ & 0.16 & $5.11 * * *$ & 0.13 & $7.52 * * *$ \\
\hline Position (P) & 0.06 & 1.43 & 0.02 & 0.62 & 0.12 & $7.37 * * *$ \\
\hline $\mathrm{R} \times \mathrm{S}$ & 0.07 & $1.85 * *$ & 0.05 & 1.70 & 0.30 & $17.51 * * *$ \\
\hline $\mathrm{R} \times \mathrm{P}$ & 0.03 & 0.74 & 0.00 & 0.15 & 0.03 & 1.56 \\
\hline $\mathrm{S} \times \mathrm{P}$ & 0.04 & 1.03 & 0.01 & 0.44 & 0.01 & 0.83 \\
\hline $\mathrm{R} \times \mathrm{S} \times \mathrm{P}$ & 0.05 & 1.19 & 0.01 & 0.34 & 0.03 & 1.48 \\
\hline Residual & 0.58 & - & 0.57 & - & 0.27 & - \\
\hline
\end{tabular}

Regions are MI and WI; Site type is either intensive or extensive; Position is either rhizosphere or bulk soil. Significance of $\mathrm{F}$ values was assessed by 9999 random permutations with the adonis function; $P<0.05 *, P<0.01 * *, P<0.001 * * *$. 
Table 2. Region, site type, and soil position effects on absolute lipid abundances ( $\mu \mathrm{g} / \mathrm{g})$ in switchgrass soils.

\begin{tabular}{lllllll}
\hline & \multicolumn{2}{c}{ Total Lipids } & \multicolumn{2}{c}{ Fungal lipids } & \multicolumn{2}{c}{ Bacterial lipids } \\
\cline { 2 - 7 } & $F$ & $p$ & $F$ & $p$ & $F$ & $p$ \\
\hline Region (R) & 8.21 & $\mathbf{0 . 0 1 4 2}$ & 9.21 & $\mathbf{0 . 0 1 0 4}$ & 8.86 & $\mathbf{0 . 0 1 1 6}$ \\
Site type (S) & 0.04 & 0.8360 & 1.04 & 0.3280 & 2.73 & 0.1243 \\
$\mathrm{R} \times \mathrm{S}$ & 0.26 & 0.6171 & 1.37 & 0.2638 & 0.25 & 0.6295 \\
Position (P) & 5.03 & $\mathbf{0 . 0 4 4 5}$ & 2.89 & 0.1147 & 4.84 & $\mathbf{0 . 0 4 8 2}$ \\
$\mathrm{R} \times \mathrm{P}$ & 0.04 & 0.8393 & 0.05 & 0.8318 & 0.23 & 0.6389 \\
\hline
\end{tabular}

Regions are MI and WI; Site type is either intensive or extensive; Position is either rhizosphere or bulk soil. Interactions of $\mathrm{S} \times \mathrm{P}$ and $\mathrm{S} \times \mathrm{R} \times \mathrm{P}$ could not be assessed with lipid data due to missing observations for rhizosphere samples from extensive sites. Values were calculated with a LMM; bolded values are significant at $p<0.05$. 
Table 3. Region and soil position effects on amino sugar abundances $(\mu \mathrm{g} / \mathrm{g})$ in intensive site switchgrass soils.

\begin{tabular}{lcccccccc}
\hline & \multicolumn{2}{c}{ GalN } & \multicolumn{2}{c}{ GluN } & \multicolumn{2}{c}{ MurA } & \multicolumn{2}{c}{ Total } \\
\cline { 2 - 8 } & F-value & p-value & F-value & p-value & F-value & p-value & F-value & p-value \\
\hline Region (R) & 1.44 & 0.316 & $\mathbf{1 0 . 8 0}$ & $\mathbf{0 . 0 4 6}$ & $\mathbf{3 7 . 1 5}$ & $\mathbf{0 . 0 0 9}$ & 8.00 & 0.066 \\
Position (P) & 9.27 & 0.056 & $\mathbf{1 6 . 4 1}$ & $\mathbf{0 . 0 2 7}$ & $\mathbf{2 3 . 8 0}$ & $\mathbf{0 . 0 1 7}$ & $\mathbf{1 4 . 5 7}$ & $\mathbf{0 . 0 3 2}$ \\
$\mathrm{R} \times \mathrm{P}$ & 1.14 & 0.364 & 5.82 & 0.095 & 1.13 & 0.365 & 4.07 & 0.137 \\
\hline Regions are & MI and WI; Position is either rhizosphere or bulk soil. Total is the sum of \\
galactosamine (GalN), glucosamine (GluN), muramic acid (MurA) and manosamine (not \\
shown). Values are based on a LMM using plot as a random effect; bolded values are \\
significant at $p<0.05$.
\end{tabular}




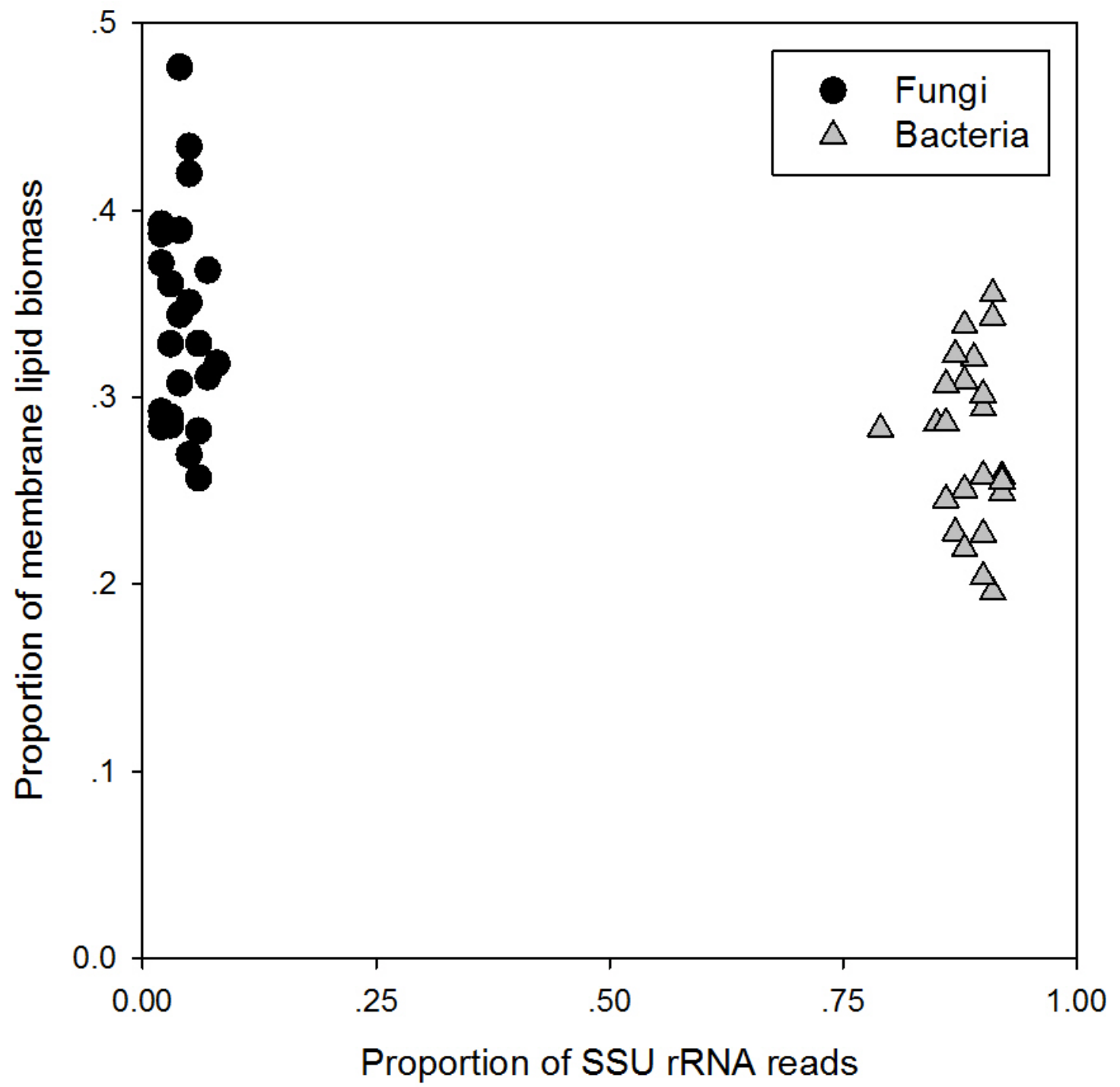




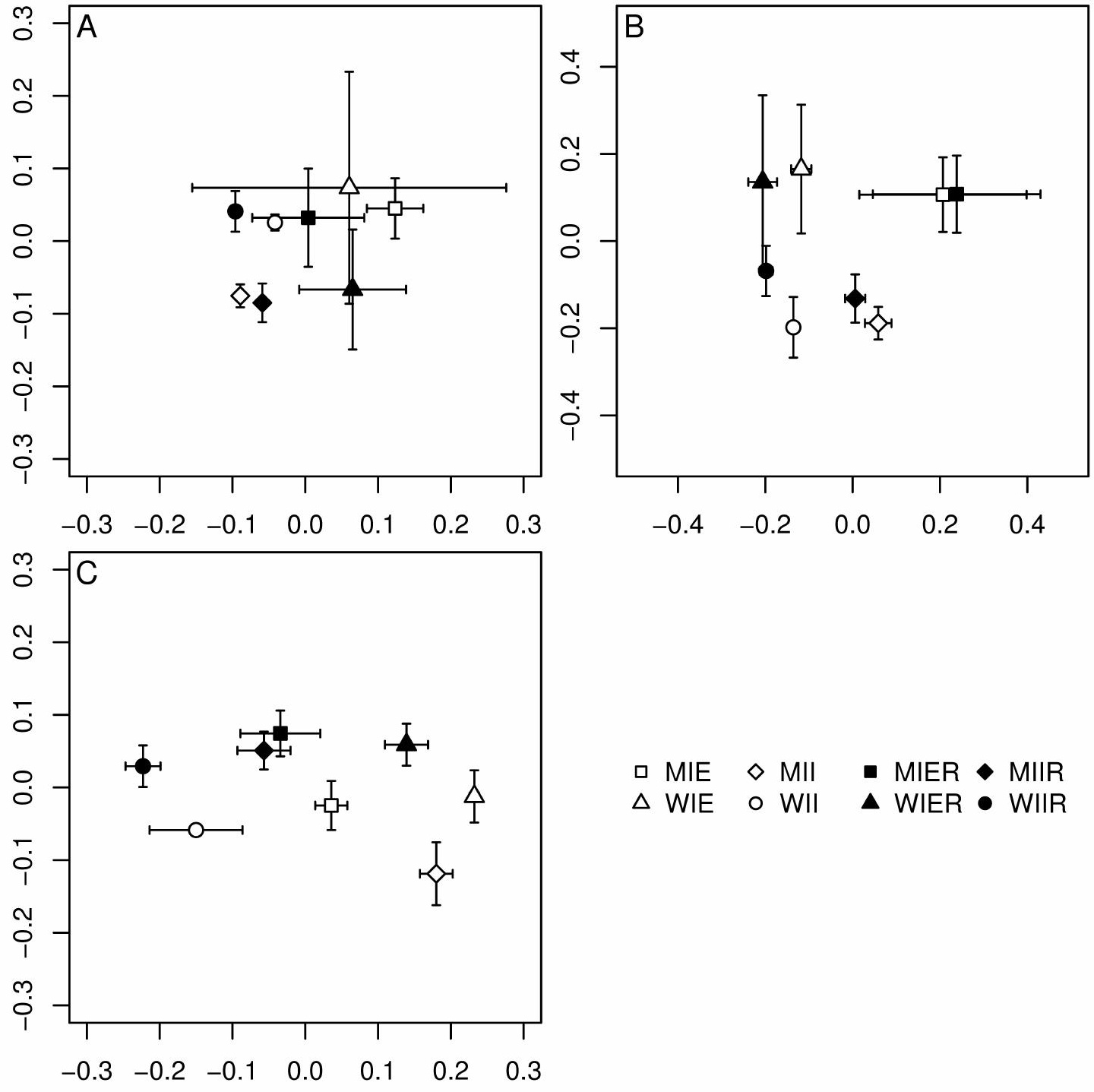




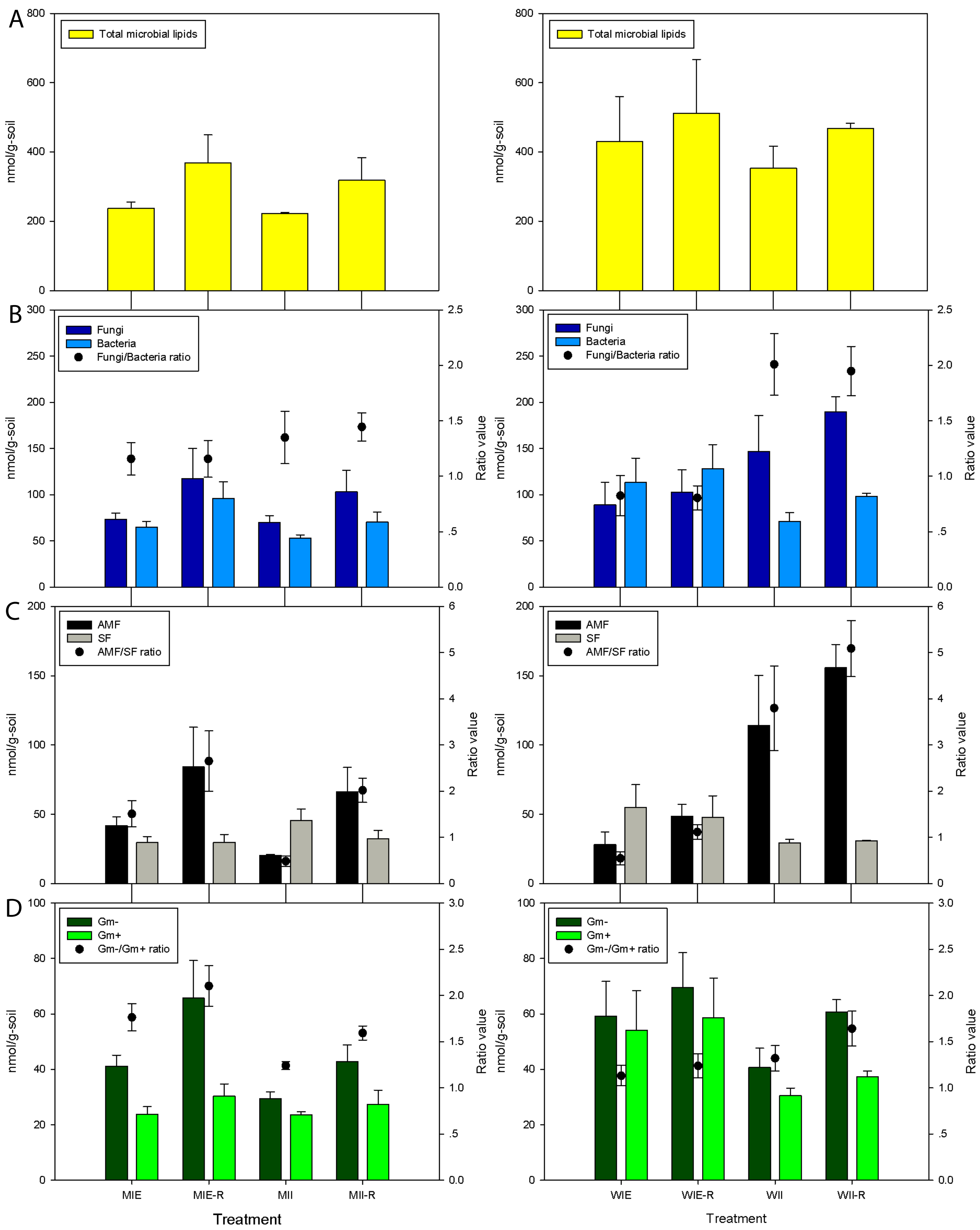




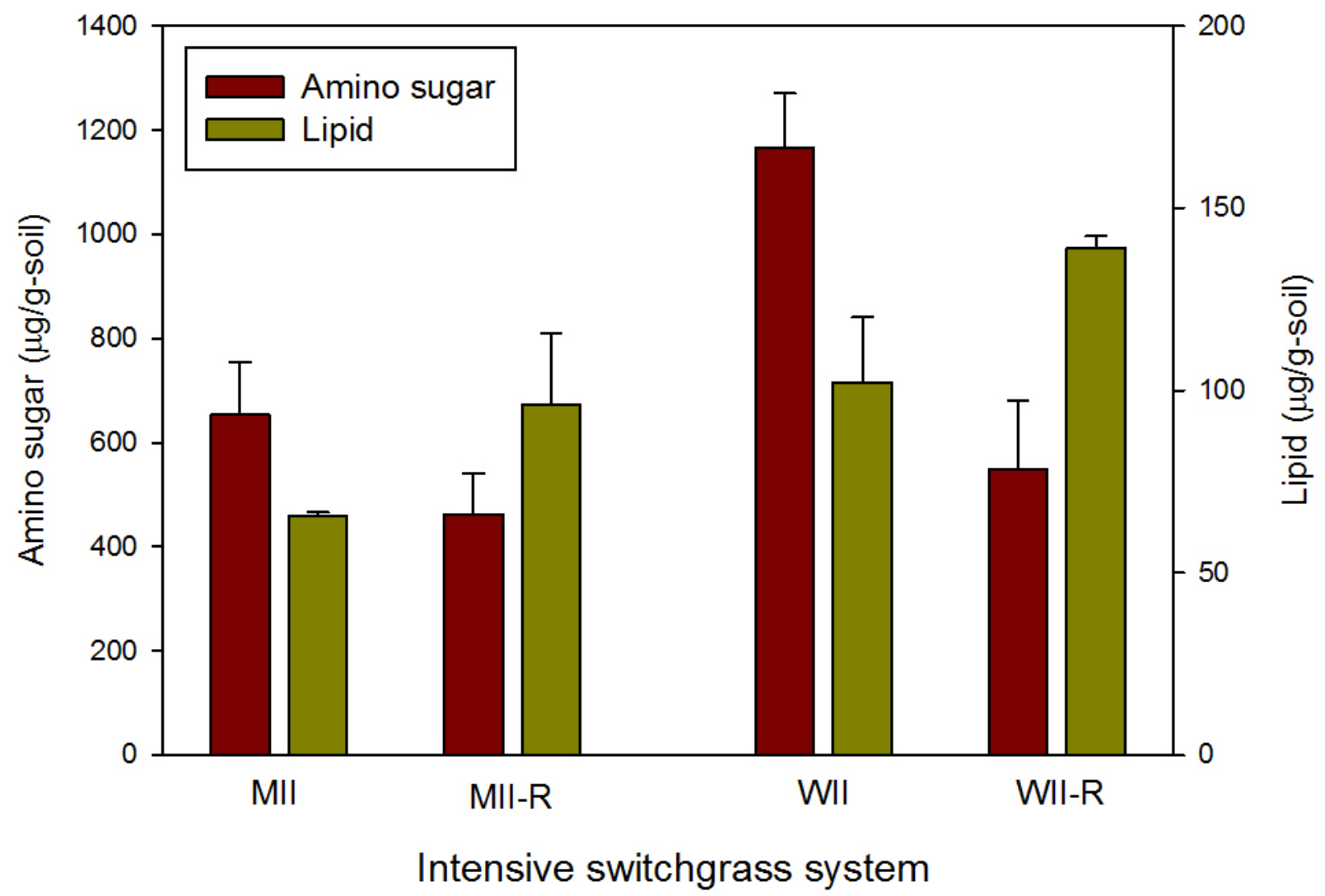

